\title{
Harm avoidance and depression, anxiety, insomnia, and migraine in fifth-year medical students in Taiwan
}

\author{
Ching-Yen Chen ${ }^{1-3}$ \\ Nan-Wen $\mathrm{Yu}^{2-4}$ \\ Tien-Hao Huang ${ }^{4}$ \\ Wei-Shin Wang ${ }^{4}$ \\ Ji-Tseng Fang 2,3,5 \\ 'Department of Psychiatry, Chang \\ Gung Memorial Hospital, Keelung, \\ Taiwan; ${ }^{2}$ School of Medicine, Chang \\ Gung University, Taoyuan, Taiwan; \\ ${ }^{3}$ Medical Education Research Center, \\ Chang Gung Memorial Hospital, \\ Taoyuan, Taiwan; ${ }^{4}$ Department of \\ Psychiatry, Chang Gung Memorial \\ Hospital, Linkou, Taiwan; ${ }^{5}$ Department \\ of Nephrology, Chang Gung Memorial \\ Hospital, Linkou, Taiwan
}

This article was published in the following Dove Press journal: Neuropsychiatric Disease and Treatment

\begin{abstract}
Purpose: During medical school training, increased stress, depression, and anxiety are common. Certain personality traits, particularly harm avoidance (HA), may increase the risk of psychopathological disorders, insomnia, and migraine among medical students. This study evaluated the role HA may play on levels of stress, depression, anxiety, and insomnia among Taiwanese medical students starting their fifth and final year of medical school.
\end{abstract}

Patients and methods: A series of self-report questionnaires were used to measure the severity of anxiety, depression, and insomnia, as well as somatic symptoms, particularly migraine headache, among 143 Taiwanese fifth-year medical students (94 males and 49 females). Most had normal or mild levels of anxiety, depression, insomnia, and migraine.

Results: HA personality trait was significantly associated with depression (all $P \leq 0.001$ ) after adjusting for other factors. HA was not significantly associated with anxiety, insomnia or migraine headache days.

Conclusion: HA personality trait was significantly associated with depression among fifth-year medical students in Taiwan.

Keywords: anxiety, depression, harm avoidance, psychological stress, sleep initiation and maintenance disorders, migraine, students, medical

\section{Introduction}

Most medical school students are challenged with some degree of stress, anxiety, depression, and burnout. ${ }^{1,2}$ Results from one of the few longitudinal studies of depression, stress, and burnout in medical students ${ }^{3}$ showed that first-year medical students have high stress levels and a high risk of depression. While burnout itself did not increase significantly, disengagement did. Burnout did not correlate with any of the personality dimensions studied.

Medical internship provides a rare chance for researchers to study the onset of major stresses since students' ages, lifestyles, and educational backgrounds are similar and they also undergo comparable stresses during medical training. Some students thrive in this environment, and their well-being is never threatened. ${ }^{4}$ Why do these students thrive during the rigors of medical school, while others struggle with stress, anxiety, and physical side effects? Can the health of all medical students be improved so that they can develop skills that will promote their well-being throughout their lives and practices? Eley et $\mathrm{al}^{4}$ noted that a number of personal competencies are crucial for success in medical practice, but these are generally neither assessed nor considered during selection of most medical schools. 
One factor in the overall health of medical students may be the individual's inherent personality traits, particularly degree of harm avoidance (HA). In 1986, psychiatrist Cloninger ${ }^{5}$ proposed a general theory of heritable personality traits and outlined the neurobiological basis for these traits. Cloninger described three independent dimensions of personality: 1) "novelty-seeking" (NS), a tendency toward frequent exploration and intense excitement in response to novel stimuli; 2) "HA", a tendency to respond intensely to aversive stimuli with learned avoidance of punishment, novelty, and non-reward in a passive manner; and 3) "reward dependence" (RD), a tendency to respond intensely to reward and social acceptance and to maintain behavior that is rewarded.

Evidence suggests that variations in each of these dimensions are strongly correlated with activity in a specific central monoaminergic pathway. HA is correlated with low serotonergic activity. HA, which features excessive worry, shyness, fearfulness, and easy fatigability, may be particularly linked to increased anxiety and depression during medical school training. It may manifest as pessimism and worry in anticipation of problems and shyness with strangers. In contrast, people with low HA scores tend to be carefree, courageous, energetic, outgoing, and optimistic, even when confronted with challenging situations. HA has also been associated with progression of parkinsonism in older adults ${ }^{6}$ and in pain-related anxiety. ${ }^{7}$

We became interested in the effects of HA among future physicians after analyzing the results of our previous study, the first to investigate the role that the HA personality trait plays in the development of depression and anxiety during medical school training. ${ }^{8}$ In that study, we found that physicians with HA personality traits were more prone to develop increased anxiety and depression during their internship than were others without HA traits. We also found that the stress during the internship period played a major role in increasing depression and anxiety and that interns with HA personality traits were more likely to develop depression and anxiety than those with NS or RD traits.

As a follow-up to our previous study, we designed a second and larger cross-sectional study to evaluate the role HA personality traits play in levels of stress, depression, anxiety, insomnia, and migraine among Taiwanese medical students starting their final year of study before beginning clinical practice. This cross-sectional study focused on students at the end of the fifth academic year; the students were in the last 2 weeks of their first year of clerkship in the Taiwanese medical training system. During this period of training, students observe procedures but are not yet directly involved with clinical procedures. Our study aimed to clarify the role of HA and other personality traits in medical students who had completed most of their preclinical studies. In addition, we sought to uncover the physical and mental conditions that medical students face at different times during training.

\section{Patients and methods}

The study group included 143 fifth-year medical students who were eligible to advance to the sixth semester at the College of Medicine, Chang Gung University, Taiwan. The study protocol was reviewed and approved by the institutional review board of Chang Gung University. All participants provided written informed consent, and the study protocol was also approved by the ethics committee of Chang-Gung Memorial Hospital.

The students were studied during the last 2 weeks of their first year of clerkship in the Taiwan medical training system, a time when students are still observing procedures and are not involved in direct patient care. The 7-year medical education program in Taiwan is similar in all 12 medical schools throughout the country. This program includes 2 years of premed courses, 2.5-3 years of clinical courses, and 2.5-3 years of clerkship and internship. The premed courses include a wide range of courses in humanism, general education, and professional ethics. Students also have service learning and community participation. During the clerkship and internship, the focus is on experience and practice. ${ }^{9}$

We administered a series of anonymous self-report questionnaires to measure the severity of psychiatric complaints, including anxiety, depression, and insomnia, as well as somatic symptoms, particularly migraine headache. The questionnaires were administered during group class periods at the end of the fifth semester in 2016, during the 2 weeks between semesters.

\section{Instruments}

The survey assessed general demographic factors (age and gender), and the following psychological questionnaires were also administered: 1) the Tridimensional Personality Questionnaire (TPQ)-HA personality subscales; 2) the Beck Depression Inventory (BDI); 3) the Beck Anxiety Inventory (BAI) and two physiological measures, the Insomnia Severity Index (ISI) and the Migraine Disability Assessment Scale (MIDAS). The BDI, BAI, ISI, and MIDAS are self-assessment tools frequently used in clinical research and have good reliability. The multicollinearity test was performed for all questionnaire variables in the BDI, BAI, 
MIDAS, and ISI. The variance inflation factor ranged from 1.07 to 1.64 (all $<10$ ), and the tolerance value ranged from 0.62 to 0.94 (all $>0.4$ ), and therefore, multicollinearity has less influence among all questionnaire variables.

\section{TPQ-HA subscales}

The TPQ is one of the best-tested tools used to investigate personality traits and is based on Cloninger's psychobiological model of personality. ${ }^{5}$ The Chinese version of the TPQ contains 100 "True" or "False" items converted into the three dimensions of NS, HA, and RD, with four subscales for each. Our group translated the TPQ into Chinese in 2002 and reported TPQ validation measures of the Taiwanese version. ${ }^{10}$ In our previous study, ${ }^{8}$ we found that only the TPQ-HA subscale showed a statistically significant association with the development of both depression and anxiety during medical internship among the three subscales of TPQ. Therefore, we also used only the TPQ-HA subscale in this study.

\section{$\mathrm{BDI}$ and $\mathrm{BAI}$}

The BDI is a widely applied, well-validated, 21-question, self-administered instrument for detecting symptoms of depression and anxiety and is used to screen individuals for clinical depression. ${ }^{11}$ The Chinese version of the BDI includes 21 statements scored on a scale from 0 to 3 . In the Chinese version of the BDI, the scores are interpreted as follows: $0-13=$ normal, $14-19=$ mild depression, $20-28=$ moderate depression, and 29-63 = severe depression. ${ }^{12}$ The BAI is a 21-question, multiple-choice, self-report inventory used for measuring the severity of anxiety. This questionnaire is designed for individuals aged 12 years or older and is composed of items relating to the symptoms of anxiety. ${ }^{13}$ The BAI is a well-validated, self-administered instrument that indicates severity of anxiety in primary care patients with varying anxiety disorders and also detects levels of depression. ${ }^{14}$ The Chinese version of the BAI includes 21 statements rated on a scale from 0 to $3 .{ }^{15}$ In this version, anxiety is scored in the following manner: 0-7, minimal anxiety; 8-15, mild anxiety; 16-25, moderate anxiety; and 26-63, severe anxiety.

\section{ISI}

The ISI is a 7-item, self-report questionnaire, which is easily administered, that assesses the severity of both nighttime and daytime components of insomnia. It is available in several languages and is increasingly used as a reliable and valid instrument to measure treatment response in clinical research. ${ }^{16,17}$
The ISI questionnaire assesses the nature, severity, and impact of insomnia. The usual recall period is the "last month", and the dimensions evaluated are severity of sleep onset, sleep maintenance, early morning awakening problems, sleep dissatisfaction, interference of sleep difficulties with daytime functioning, noticeability of sleep problems by others, and distress caused by the sleep difficulties. A 5-point Likert scale is used to rate each item (ranging from 0 , no problem, to 4 , very severe problem), yielding a total score ranging from 0 to 28 . The total score is interpreted as follows: 0-7, absence of insomnia, 8-14, subthreshold insomnia, 15-21, moderate insomnia, and 22-28, severe insomnia. The ISI was translated into Chinese for this study. There are no reports on the reliability and validity of a Chinese version of the ISI.

\section{MIDAS}

The MIDAS questionnaire is a reliable and valid, short, self-administered questionnaire that is easy to administer and is designed to quantify headache-related disability over a 3-month period. ${ }^{18}$ MIDAS has been validated in varied populations and can differentiate episodic and chronic headache. ${ }^{19}$

Headache sufferers answer five questions and score the number of days in the past 3 months when their activities were limited by migraine headache. The MIDAS score is based on five disability questions in three dimensions. Questions 1 and 2 assess the number of missed days or significant limitations to activity (defined as at least $50 \%$ reduced productivity) due to headache during school or during paid work activities (school/job dimension). Questions 3 and 4 assess the number of days of missed or significant limitations to activity (defined as productivity reduced by at least 50\%) due to headache in housework activities (housework dimension). Question 5 assesses days missed due to headache during family, social, or leisure activities (social dimension). The MIDAS score is the sum of responses to questions 1 to 5. Two supplemental questions (A and B) provide the examiner with additional clinical information about headache frequency and the average pain intensity (scale: $0-10$ ) of headaches over the previous 3 months. For this study, the MIDAS was translated into Chinese. The reliability and validity of a Chinese version of the MIDAS has not been reported.

\section{Statistical analyses}

The total scores of the TPQ, BAI, BDI, ISI, and MIDAS questionnaires were included as continuous variables and 
grouped into four levels according to severity. The coefficient alphas ranged from 0.80 to 0.88 for the five questionnaires. The individual coefficient alphas for all measures in this study were as follows: for the TPQ, 0.87; for the BAI, 0.84; for the BDI, 0.88; for the ISI, 0.88; and for the MIDAS (five items), 0.80. Each questionnaire had a relatively high internal consistency. Continuous variables were presented as mean and standard deviation (SD) values. Categorical variables were presented as counts and percentages. Univariate and multivariate linear regression analyses were performed to investigate which factors were associated with headache, anxiety, depression, insomnia, and migraine disability. Factors significantly associated with outcome in univariate analyses were included in a multivariate model. Since the HA score on the TPQ was the primary factor, it was included in multivariate analysis whether it was significant or not. The power analysis was used to determine the sample size. Using our previous study as the test value, ${ }^{8}$ the power was presented as $82.5 \%$ and $100 \%$, and $>80 \%$ showed the good level of power.

Statistical analyses were performed by IBM SPSS Statistical Software Version 22 for Windows (IBM Corporation, Armonk, NY, USA), and a two-tailed $P<0.05$ indicated statistical significance.

\section{Results}

\section{Demographic distribution}

A total of 143 medical students (94 males and 49 females) were included in this study, and the response rate was $100 \%$. The mean age was 23.5 years. Most subjects had normal or mild levels of anxiety, depression, insomnia, and migraine disability (all reported as $>90 \%$ ). Subjects with migraine headache reported an average of 3.46 days of migraine headache, and the mean level of migraine on the MIDAS was 1.75 (Table 1).

\section{Factors associated with headache days}

According to univariate analyses, anxiety, depression, insomnia, and migraine disability scores were all significantly associated with headache days (all $P \leq 0.001$ ). No significant association was found between the HA score and the number of headache days (Table 2).

Headache days were significantly increased when the anxiety, depression, insomnia, and migraine disability scores were also increased. For the multivariable analyses, the anxiety and migraine disability scores were significantly associated with headache days, after adjusting for the HA
Table I Characteristics of study participants

\begin{tabular}{|c|c|}
\hline Characteristics & Total $(N=143)$ \\
\hline \multicolumn{2}{|l|}{ Gender, n (\%) } \\
\hline Male & $94(65.73)$ \\
\hline Female & $49(34.27)$ \\
\hline Age (years), mean \pm SD & $23.53 \pm 1.88$ \\
\hline HA score, mean \pm SD & $17.47 \pm 6.83$ \\
\hline Anxiety score, mean $\pm S D$ & $5.38 \pm 5.04$ \\
\hline \multicolumn{2}{|l|}{ Anxiety level, n (\%) } \\
\hline Slight & $109(76.22)$ \\
\hline Mild & $28(19.58)$ \\
\hline Moderate & $6(4.2)$ \\
\hline Severe & $0(0)$ \\
\hline Depression score, mean \pm SD & $6.84 \pm 6.07$ \\
\hline \multicolumn{2}{|l|}{ Depression level, n (\%) } \\
\hline Normal & $120(83.92)$ \\
\hline Mild & $17(\mid 1.89)$ \\
\hline Moderate & $5(3.5)$ \\
\hline Severe & $\mathrm{I}(0.7)$ \\
\hline Insomnia score, mean \pm SD & $5.18 \pm 4.43$ \\
\hline \multicolumn{2}{|l|}{ Insomnia frequency, n (\%) } \\
\hline None & $108(75.52)$ \\
\hline Initial & $31(21.68)$ \\
\hline Intermediate & $3(2.1)$ \\
\hline End of study & $\mathrm{I}(0.7)$ \\
\hline Migraine disability score, mean \pm SD & $2.85 \pm 6.59$ \\
\hline \multicolumn{2}{|l|}{ Migraine disability level, n (\%) } \\
\hline Little/none & II 8 (82.52) \\
\hline Mild & $12(8.45)$ \\
\hline Moderate & $9(6.34)$ \\
\hline Severe & $4(2.8)$ \\
\hline MIDAS: days of headache, mean \pm SD & $3.46 \pm 7.94$ \\
\hline MIDAS: level of headache, mean \pm SD & $1.75 \pm 2.04$ \\
\hline
\end{tabular}

Abbreviations: SD, standard deviation; HA, harm avoidance; MIDAS, Migraine Disability Assessment Scale.

score, depression score, and insomnia score. The headache days were significantly increased when the anxiety score and migraine disability score increased and when the HA score, depression score, and insomnia score were adjusted.

Table 2 Factors associated with headache days

\begin{tabular}{|c|c|c|c|c|}
\hline \multirow[t]{2}{*}{ Characteristics } & \multicolumn{2}{|l|}{ Univariate } & \multicolumn{2}{|l|}{ Multivariate } \\
\hline & $\beta \pm \mathbf{S E}$ & $P$-value & $\begin{array}{l}\text { Adjusted } \\
\beta \pm \text { SE }\end{array}$ & $P$-value \\
\hline \multicolumn{5}{|l|}{ Gender } \\
\hline Male & $-2.03 \pm 1.39$ & 0.147 & & \\
\hline Female & Reference & & & \\
\hline Age (years) & $-0.35 \pm 0.35$ & 0.328 & & \\
\hline HA score & $0.13 \pm 0.1$ & 0.188 & $-0.07 \pm 0.09$ & 0.419 \\
\hline Anxiety score & $0.62 \pm 0.12$ & $<0.001 *$ & $0.35 \pm 0.14$ & $0.013 *$ \\
\hline Depression score & $0.4 \pm 0.1$ & $<0.001 *$ & $0.08 \pm 0.12$ & 0.507 \\
\hline Insomnia score & $0.47 \pm 0.15$ & $0.00 I^{*}$ & $0.2 \pm 0.14$ & 0.171 \\
\hline Migraine disability score & $0.63 \pm 0.09$ & $<0.001 *$ & $0.56 \pm 0.08$ & $<0.001 *$ \\
\hline
\end{tabular}

Note: $* P<0.05$, factor significantly associated with headache days. Abbreviations: SE, standard error; HA, harm avoidance. 


\section{Factors associated with anxiety}

Univariate analysis showed that age, HA score, depression score, insomnia score, migraine disability score, and days of headache were all significantly associated with anxiety (all $P \leq 0.019$; Table 3). The anxiety score decreased with increasing age and increased with rises in the HA score, depression score, insomnia score, migraine disability score, and days of headache.

For the multivariable analyses, age, depression score, insomnia score, and days of headache were significantly associated with anxiety after adjusting for HA score and migraine disability score. The anxiety score decreased as age increased and increased with the depression score, insomnia score, and days of headache. No significant association was found with the HA score.

\section{Factors associated with depression}

According to the univariate analyses, the HA score was found to be significantly associated with depression $(\beta=0.37$, $P<0.001)$. The anxiety score, insomnia score, migraine disability score, and days and level of headache were also associated with depression (all $P \leq 0.015$; Table 4).

For the multivariable analyses, the HA score was significantly associated with depression after adjusting for the migraine disability scores and the days and level of headache. The anxiety score and insomnia score were also significantly associated with depression after the same adjustments.

\section{Factors associated with insomnia}

According to univariate analyses, the HA, anxiety, and depression scores and days of headache were all found to

Table 3 Factors associated with anxiety

\begin{tabular}{|c|c|c|c|c|}
\hline \multirow[t]{2}{*}{ Characteristics } & \multicolumn{2}{|l|}{ Univariate } & \multicolumn{2}{|c|}{ Multivariate } \\
\hline & $\beta \pm \mathbf{S E}$ & $P$-value & $\begin{array}{l}\text { Adjusted } \\
\beta \pm \mathbf{S E}\end{array}$ & $P$-value \\
\hline \multicolumn{5}{|l|}{ Gender } \\
\hline Male & $-1.09 \pm 0.89$ & 0.221 & & \\
\hline Female & Reference & & & \\
\hline Age (years) & $-0.53 \pm 0.22$ & $0.019 *$ & $-0.36 \pm 0.18$ & $0.045^{*}$ \\
\hline HA score & $0.23 \pm 0.06$ & $<0.001 *$ & $0.05 \pm 0.05$ & 0.352 \\
\hline Depression score & $0.48 \pm 0.06$ & $<0.00 I^{*}$ & $0.31 \pm 0.07$ & $<0.00 I^{*}$ \\
\hline Insomnia score & $0.51 \pm 0.09$ & $<0.00 I^{*}$ & $0.23 \pm 0.08$ & $0.007^{*}$ \\
\hline $\begin{array}{l}\text { Migraine disability } \\
\text { score }\end{array}$ & $0.18 \pm 0.06$ & $0.005^{*}$ & $0.01 \pm 0.06$ & 0.888 \\
\hline $\begin{array}{l}\text { MIDAS: days of } \\
\text { headache }\end{array}$ & $0.25 \pm 0.05$ & $<0.00$ I* $^{*}$ & $0.13 \pm 0.05$ & $0.013^{*}$ \\
\hline $\begin{array}{l}\text { MIDAS: level of } \\
\text { headache }\end{array}$ & $0.4 \pm 0.21$ & 0.052 & & \\
\hline
\end{tabular}

Note: $* P<0.05$, factor significantly associated with anxiety.

Abbreviations: SE, standard error; HA, harm avoidance; MIDAS, Migraine Disability Assessment Scale.
Table 4 Factors associated with depression

\begin{tabular}{|c|c|c|c|c|}
\hline \multirow[t]{2}{*}{ Characteristics } & \multicolumn{2}{|l|}{ Univariate } & \multicolumn{2}{|l|}{ Multivariate } \\
\hline & $\beta \pm \mathbf{S E}$ & $P$-value & $\begin{array}{l}\text { Adjusted } \\
\beta \pm \mathrm{SE}\end{array}$ & $P$-value \\
\hline \multicolumn{5}{|l|}{ Gender } \\
\hline Male & $-0.74 \pm 1.07$ & 0.490 & & \\
\hline Female & Reference & & & \\
\hline Age (years) & $-0.23 \pm 0.27$ & 0.393 & & \\
\hline HA score & $0.37 \pm 0.07$ & $<0.00 I^{*}$ & $0.22 \pm 0.06$ & $<0.00 I^{*}$ \\
\hline Anxiety score & $0.69 \pm 0.08$ & $<0.00 I^{*}$ & $0.42 \pm 0.09$ & $<0.001 *$ \\
\hline Insomnia score & $0.64 \pm 0.10$ & $<0.00 I^{*}$ & $0.33 \pm 0.10$ & $0.00 I^{*}$ \\
\hline $\begin{array}{l}\text { Migraine } \\
\text { disability score }\end{array}$ & $0.19 \pm 0.08$ & $0.015^{*}$ & $0.005 \pm 0.07$ & 0.948 \\
\hline $\begin{array}{l}\text { MIDAS: days of } \\
\text { headache }\end{array}$ & $0.23 \pm 0.06$ & $<0.00 I^{*}$ & $0.03 \pm 0.06$ & 0.598 \\
\hline $\begin{array}{l}\text { MIDAS: level of } \\
\text { headache }\end{array}$ & $0.61 \pm 0.25$ & $0.015^{*}$ & $0.28 \pm 0.21$ & 0.190 \\
\hline
\end{tabular}

Note: $* P<0.05$, significantly associated with depression.

Abbreviations: SE, standard error; HA, harm avoidance; MIDAS, Migraine Disability Assessment Scale.

be significantly associated with insomnia (all $P \leq 0.026$; Table 5). The insomnia score was significantly increased with the HA score, anxiety score, depression score, and days of headache.

For the multivariable analyses, the anxiety score and depression score were significantly associated with insomnia after adjusting for HA and days of headache. The insomnia score was significantly increased with the anxiety score, and the depression score increased after adjustment for HA and days of headache.

\section{Correlation matrix for multivariate analysis results}

A correlation matrix for the results of multivariate regression analysis is presented in Table 6 . This matrix includes

Table 5 Factors associated with insomnia

\begin{tabular}{llllll}
\hline Characteristics & \multicolumn{2}{l}{ Univariate } & & \multicolumn{2}{l}{ Multivariate } \\
\cline { 2 - 3 } \cline { 5 - 6 } & $\boldsymbol{\beta} \pm \mathbf{S E}$ & $\boldsymbol{P}$-value & $\begin{array}{l}\text { Adjusted } \\
\boldsymbol{\beta} \pm \mathbf{S E}\end{array}$ & $\boldsymbol{P}$-value \\
\hline Gender & & & & & \\
$\quad$ Male & & & & & \\
$\quad$ Female & & Reference & & & \\
Age (years) & $-0.05 \pm 0.2$ & 0.812 & & \\
HA score & $0.12 \pm 0.05$ & $0.026^{*}$ & & $-0.02 \pm 0.05$ & 0.684 \\
Anxiety score & $0.39 \pm 0.07$ & $<0.00 I^{*}$ & $0.22 \pm 0.08$ & $0.009^{*}$ \\
Depression score & $0.34 \pm 0.05$ & $<0.00 I^{*}$ & $0.23 \pm 0.07$ & $0.00 I^{*}$ \\
Migraine disability score & $0.06 \pm 0.06$ & 0.312 & & \\
MIDAS: days of headache & $0.15 \pm 0.05$ & $0.00 I^{*}$ & $0.04 \pm 0.04$ & 0.356 \\
MIDAS: level of headache & $0.19 \pm 0.18$ & 0.289 & &
\end{tabular}

Note: $* P<0.05$, significantly associated with insomnia.

Abbreviations: SE, standard error; HA, harm avoidance; MIDAS, Migraine Disability Assessment Scale. 
Table 6 Correlation matrix for multivariate regression analysis results

\begin{tabular}{|c|c|c|c|c|c|c|}
\hline Characteristics & Statistics & $\begin{array}{l}\text { MIDAS: days } \\
\text { of headache }\end{array}$ & $\begin{array}{l}\text { HA } \\
\text { score }\end{array}$ & $\begin{array}{l}\text { Depression } \\
\text { score }\end{array}$ & $\begin{array}{l}\text { Anxiety } \\
\text { score }\end{array}$ & $\begin{array}{l}\text { Migraine } \\
\text { disability score }\end{array}$ \\
\hline \multirow[t]{2}{*}{ MIDAS: days of headache } & Pearson $\gamma$ & 1 & & & & \\
\hline & $P$-value & - & & & & \\
\hline \multirow[t]{2}{*}{ HA score } & Pearson $\gamma$ & -0.04 & I & & & \\
\hline & $P$-value & 0.632 & - & & & \\
\hline \multirow[t]{2}{*}{ Depression score } & Pearson $\gamma$ & 0.306 & -0.035 & I & & \\
\hline & $P$-value & $0.0002 *$ & 0.681 & - & & \\
\hline \multirow[t]{2}{*}{ Anxiety score } & Pearson $\gamma$ & 0.392 & -0.018 & 0.573 & 1 & \\
\hline & $P$-value & $<0.001 *$ & 0.835 & $<0.00 I^{*}$ & - & \\
\hline \multirow[t]{2}{*}{ Migraine disability score } & Pearson $\gamma$ & 0.526 & -0.051 & 0.203 & 0.235 & 1 \\
\hline & $P$-value & $<0.001 *$ & 0.542 & $0.015 *$ & $0.005^{*}$ & - \\
\hline
\end{tabular}

Note: *Significant correlation.

Abbreviations: MIDAS, Migraine Disability Assessment Scale; HA, harm avoidance.

the correlation among the results described earlier for all the factors analyzed.

\section{Discussion}

Fifth-year medical students in Taiwan identified as having the HA personality trait had significantly higher scores only on measures of depression; HA was not associated with the anxiety score, insomnia score, and days and level of headache. This contrasted with the results of our previous study of medical students, ${ }^{8}$ where levels of both depression and anxiety increased (6.4 and 3.4 on scores for the BDI and BAI, respectively) during their internship and then returned to baseline levels 2 weeks after their internship ended.

The difference in depression and anxiety scores between the two study groups may have been related to the fact that subjects in the earlier study were all seventh-year interns, which is at a time in their studies when stress is relatively high. In contrast, students in the current study are fifthyear medical students who had just left a conventional classroom-only environment to begin their internship. The stress is relatively low during the fifth and sixth years of study but increases to a high level throughout the seventh year, when interns are often on duty at a hospital and become involved in actual clinical care. In our earlier study, only the TPQ-HA subscale showed statistically significant increases associated with the development of both depression and anxiety during medical internship training.

A few other authors have evaluated the effects of personality traits on stress among medical students. Eley et a $1^{4}$ studied personality and character traits among 808 medical students from the University of Queensland, Australia, and identified two distinct personality profiles. The first profile, defined as "Resilient", was identified in $60 \%$ of students and was distinguished with lower levels of HA combined with very high levels of persistence, cooperation, self-directedness, and creativity. The second profile was defined as "Conscientious". These students were more anxious and less resilient than those with the Resilient profile. The authors concluded that physicians need to be fairly resilient with a high persistence and high self-directedness and/or low levels of HA.

Researchers in the Mayo Clinic IMWELL study ${ }^{20}$ analyzed 202 medical residents and reported that some interpersonal factors did influence the residents' well-being and clinical performance. However, multiple dimensions of resident performance assessment were not significantly influenced by well-being, including quality of life measures and depression measures.

A few additional authors have analyzed personality traits and migraine, anxiety, depression, and insomnia in medical students and also in patients.

- Migraine: in a study of Mexican patients with migraine, ${ }^{21}$ results on the temperament and character inventory showed that patients with migraine had higher scores on the HA dimension and all its subdimensions than did healthy patients. In addition, patients with non-migraine pain had high HA scores and low scores in NS, selfdirectedness, and cooperativeness.

- Anxiety and depression: when Leombruni et a ${ }^{22}$ evaluated attitudes of medical students toward caring for dying patients, the authors identified a significant link between more self-directed and lower HA personality profiles and more developed attitudes toward dying patients.

- Insomnia: Park et $\mathrm{al}^{23}$ found that various dimensions of personality were associated with the severity of insomnia and that "internalizing behavior" and depression might be a more plausible link between personality and insomnia than is anxiety.

As other studies have shown, there is a need for personality assessment as part of the medical school curricula to help future physicians develop patient-centered practices. ${ }^{22}$ 
Programs that develop character and personality self-awareness could enhance students' well-being and also prepare them to promote the health of their patients. ${ }^{4}$

Finally, helping medical students learn to better cope with stress through self-directed learning may improve their quality of life and their medical education. In a recent study, Liu et $\mathrm{al}^{24}$ evaluated a group of medical interns at a teaching hospital in northern Taiwan. Most students encountered increasing stress, such as a growing sense of responsibility, coping with uncertainty, and challenging interpersonal professional relationships, during their transition from observer status to full-time medical practitioners. Using a self-directed learning strategy, the students began to work with actual patients instead of merely observing medical procedures. They also began applying their knowledge and skills in the "real world" and could see how these were directly related to their patients' care and well-being.

\section{Study limitations}

Our study did have a few limitations. First, the sample size was small, 143 students, and the students were recruited from only one site, Chang Gung University. However, the medical education program at this university is similar to that at all the other medical schools in Taiwan, and thus, responses can be viewed as representative of medical students throughout Taiwan. Second, the psychosomatic considerations of a medical school population might have been more extensive with a more comprehensive approach. Our previous study was made of seventh-year medical students, and the seventh year is recognized as the most stressful academic year. The current study is based on fifth-year medical students; the fourth year involves only classroom study and the hospital trainee stage begins in the fifth year. Moreover, the data were derived from self-report questionnaires, not from medical records. This might have resulted in some recall bias. Another limitation was the study design as this was a cross-sectional study and therefore may not have been representative as it did not provide data over an extended period of time. Finally, only a HA personality assessment was used in the study. In our previous study, we found that only the TPQ-HA subscale showed a statistically significant association with the development of both depression and anxiety during medical internship. Therefore, we only used the TPQ-HA subscale in our current study. In addition, this was done partly because of convenience and feasibility as it would have been difficult to obtain complete responses from the subjects had the NS and RD personality traits have also been fully investigated. Future studies may provide a more thorough evaluation of personality and somatic symptoms among medical students at different stages of their education and may lead to measures that may help students deal better with the stresses inherent in medical training.

\section{Acknowledgments}

The authors also would like to thank all participants. This study was funded by the Chang Gung Hospital (No CDRPG3F0011).

\section{Author contributions}

All authors contributed toward data analysis, drafting and revising the paper and agreed to be accountable for all aspects of the work.

\section{Disclosure}

The authors report no conflicts of interest in this work.

\section{References}

1. Shanafelt TD, Bradley KA, Wipf JE, Back AL. Burnout and selfreported patient care in an internal medicine residency program. Ann Intern Med. 2002;136(5):358-367.

2. Schneider SE, Phillips WM. Depression and anxiety in medical, surgical, and pediatric interns. Psychol Rep. 1993;72(3 pt 2):1145-1146.

3. Goel AD, Akarte SV, Agrawal SP, Yadav V. Longitudinal assessment of depression, stress, and burnout in medical students. J Neurosci Rural Pract. 2016;7(4):493-498.

4. Eley DS, Leung J, Hong BA, Cloninger KM, Cloninger CR. Identifying the dominant personality profiles in medical students: implications for their well-being and resilience. PLoS One. 2016;11(8):e0160028.

5. Cloninger $\mathrm{CR}$. A unified biosocial theory of personality and its role in the development of anxiety states. Psychiatr Dev. 1986;4(3):167-226.

6. Buchman AS, Yu L, Wilson RS, Shulman JM, Boyle PA, Bennett DA. Harm avoidance is associated with progression of parkinsonism in community-dwelling older adults: a prospective cohort study. $B M C$ Geriatr. 2014;14:54.

7. Knaster P, Estlander AM, Karlsson H, Kaprio J, Kalso E. Temperament traits and chronic pain: the association of harm avoidance and pain-related anxiety. PLoS One. 2012;7(10):e45672.

8. Chen CY, Lin SH, Li P, Huang WL, Lin YH. The role of the harm avoidance personality in depression and anxiety during the medical internship. Medicine (Baltimore). 2015;94(2):e389.

9. Chou JY, Chiu CH, Lai E, Tsai D, Tzeng CR. Medical education in Taiwan. Med Teach. 2012;34(3):187-191.

10. Chen WJ, Chen HM, Chen CC, Chen CC, Yu WY, Cheng AT. Cloninger's tridimensional personality questionnaire: psychometric properties and construct validity in Taiwanese adults. Compr Psychiatry. 2002;43(2): 158-166.

11. Beck AT. A systematic investigation of depression. Compr Psychiatry. 1961;2(3):163-170.

12. Shek DT. Reliability and factorial structure of the Chinese version of the beck depression inventory. J Clin Psychol. 1990;46(1):35-43.

13. Beck AT, Epstein N, Brown G, Steer RA. An inventory for measuring clinical anxiety: psychometric properties. J Consult Clin Psychol. 1988; 56(6):893-897.

14. Muntingh $A D$, van der Feltz-Cornelis CM, van Marwijk HW, Spinhoven $P$, Penninx BW, van Balkom AJ. Is the Beck Anxiety Inventory a good tool to assess the severity of anxiety? A primary care study in the Netherlands Study of Depression and Anxiety (NESDA). BMC Fam Pract. 2011;12:66. 
15. Che HHLM, Chen HC, Chang SW, Lee YJ. Validation of the Chinese version of the Beck Anxiety Inventory. Formos J Med. 2006;10(4): $447-454$.

16. Bastien CH, Vallieres A, Morin CM. Validation of the insomnia severity index as an outcome measure for insomnia research. Sleep Med. 2001; 2(4):297-307.

17. Morin CM, Belleville G, Belanger L, Ivers H. The insomnia severity index: psychometric indicators to detect insomnia cases and evaluate treatment response. Sleep. 2011;34(5):601-608.

18. Stewart WF, Lipton RB, Dowson AJ, Sawyer J. Development and testing of the migraine disability assessment (MIDAS) questionnaire to assess headache-related disability. Neurology. 2001;56(6 suppl 1):S20-S28.

19. Zandifar A, Asgari F, Haghdoost F, et al. Reliability and validity of the migraine disability assessment scale among migraine and tension type headache in Iranian patients. Biomed Res Int. 2014;2014:978064.

20. Beckman TJ, Reed DA, Shanafelt TD, West CP. Resident physician well-being and assessments of their knowledge and clinical performance. J Gen Intern Med. 2012;27(3):325-330.
21. Sanchez-Roman S, Tellez-Zenteno JF, Zermeno-Phols F, et al. Personality in patients with migraine evaluated with the "temperament and character inventory". J Headache Pain. 2007;8(2):94-104.

22. Leombruni P, Miniotti M, Zizzi F, et al. Attitudes of medical students toward the care of the dying in relation to personality traits: harm avoidance and self-directedness make a difference. Am J Hosp Palliat Care. 2015;32(8):824-828.

23. Park JH, An H, Jang ES, Chung S. The influence of personality and dysfunctional sleep-related cognitions on the severity of insomnia. Psychiatry Res. 2012;197(3):275-279.

24. Liu CH, Tang WR, Weng WH, Lin YH, Chen CY. The process of coping with stress by Taiwanese medical interns: a qualitative study. BMC Med Educ. 2016;16:10.

\section{Publish your work in this journal}

Neuropsychiatric Disease and Treatment is an international, peerreviewed journal of clinical therapeutics and pharmacology focusing on concise rapid reporting of clinical or pre-clinical studies on a range of neuropsychiatric and neurological disorders. This journal is indexed on PubMed Central, the 'PsycINFO' database and CAS, and is the official journal of The International Neuropsychiatric Association (INA). The manuscript management system is completely online and includes a very quick and fair peer-review system, which is all easy to use. Visit http://www.dovepress.com/testimonials.php to read real quotes from published authors. 